\title{
Clostridium butyricum MIYAIRI 588 shows antitumor effects by enhancing the release of TRAIL from neutrophils through MMP-8
}

\author{
MASAHIDE SHINNOH ${ }^{1,2^{*}}$, MANO HORINAKA $^{1 *}$, TAKASHI YASUDA $^{1,2}$, SAE YOSHIKAWA $^{1}$, \\ MIE MORITA $^{1}$, TAKESHI YAMADA ${ }^{1,2}$, TSUNEHARU MIKI ${ }^{2}$ and TOSHIYUKI SAKAI ${ }^{1}$ \\ Departments of ${ }^{1}$ Molecular-Targeting Cancer Prevention and ${ }^{2}$ Urology, Kyoto Prefectural \\ University of Medicine, Kawaramachi-Hirokoji, Kamigyo-ku, Kyoto 602-8566, Japan
}

Received November 2, 2012; Accepted December 14, 2012

DOI: $10.3892 /$ ijo. 2013.1790

\begin{abstract}
Bacillus Calmette-Guérin (BCG) intravesical therapy against superficial bladder cancer is one of the most successful immunotherapies in cancer, though the precise mechanism has not been clarified. Recent studies have demonstrated urinary tumor necrosis factor-related apoptosisinducing ligand (TRAIL) levels to be higher in BCG-responsive patients than non-responders and shown that polymorphonuclear neutrophils (PMNs) migrating to the bladder after BCG instillation release large amounts of TRAIL. To establish a safer and more effective intravesical therapy than BCG, we examined whether other bacteria induced similar effects. We stimulated PMNs or peripheral blood mononuclear cells (PBMCs) with BCG or other bacteria, and then aliquots of the culture supernatants or cell lysates were assayed for TRAIL. We examined the signaling pathway regulating the release of TRAIL from PMNs and evaluated the antitumor effects of BCG or other bacteria in vitro and in vivo. We have found that Clostridium butyricum MIYAIRI 588 (CBM588) induces the release of endogenous TRAIL from PMNs as well as BCG. In addition, we have shown that matrix metalloproteinase 8 (MMP-8) is one of the key factors responsible for the release. Interestingly, TLR2/4 signaling pathway has been suggested to be important for the release of TRAIL by MMP- 8 . CBM588
\end{abstract}

Correspondence to: Dr Toshiyuki Sakai, Department of MolecularTargeting Cancer Prevention, Graduate School of Medical Science, Kyoto Prefectural University of Medicine, Kawaramachi-Hirokoji, Kamigyo-ku, Kyoto 602-8566, Japan

E-mail: tsakai@koto.kpu-m.ac.jp

*Contributed equally

Abbreviations: CBM588, Clostridium butyricum MIYAIRI 588; BCG, Bacillus Calmette-Guérin; PMN, polymorphonuclear neutrophil; PBMC, peripheral blood mononuclear cell; MMP, matrix metalloproteinase; TRAIL, tumor necrosis factor-related apoptosisinducing ligand; TLR, toll-like receptor

Key words: Clostridium butyricum MIYAIRI 588, BCG, bladder cancer, TRAIL, MMP-8 has been proven to be as effective as BCG against cancer cells by inducing apoptosis in vivo as well as in vitro. Taken together, these results strongly suggest that CBM588 is promising for a safer and more effective therapy against bladder cancer.

\section{Introduction}

Bladder cancer is one of the most common malignant tumors in the United States (1). Approximately $70 \%$ of newly diagnosed bladder cancers are of the superficial type (2). A mainstay of therapy for superficial bladder cancer is complete transurethral resection. However, bladder cancer locally relapses in $70 \%$ of patients, and progresses to muscle invasive cancer after transurethral resection in $30 \%$. To reduce this recurrence and progression, intravesical instillation of antitumor agents has been used since the early seventies (3).

Bacillus Calmette-Guérin (BCG) was isolated from Mycobacterium bovis which caused bovine tuberculosis in 1921 (4). Since the intravesical instillation of BCG for bladder cancer therapy was first reported in 1976 (5), it has become the most successful immunotherapy for non-invasive bladder cancer (6). However, the instillation of BCG has serious side effects, such as disseminated infections, sepsis and multiple organ failure $(7,8)$. Therefore, the discovery of other bacteria which have the same anticancer effects with less side effects is required for bladder cancer patients. Indeed, intravesical treatments with other bacteria have been reported $(9,10)$.

Although BCG intravesical therapy is one of the most successful immunotherapies, its precise mechanism is still unknown. Recently, it has been reported that the concentration of urinary tumor necrosis factor-related apoptosis-inducing ligand (TRAIL) was higher in BCG-responsive patients than non-responders (11). Furthermore, polymorphonuclear neutrophils (PMNs) migrating to the bladder after BCG instillation release large amounts of TRAIL (12). TRAIL is a cytokine inducing apoptosis in malignant tumor cells without affecting normal cells (13-15) and is considered a promising anticancer agent in clinical trials $(16,17)$.

It has been reported that matrix metalloproteinases (MMPs) stimulate the release of cytokines and chemokines via proteolytic processing (18-20). Other proteases, such as a disintegrin and metalloproteases (ADAMs) or cathepsin E, have been also reported to be required for shedding of cyto- 
kines from the cell surface $(21,22)$. However, little is known about the mechanism of TRAIL release in PMNs (23).

In this study, we have found that Clostridium butyricum MIYAIRI 588 (CBM588) induces the release of TRAIL from PMNs, resulting in marked anticancer effects in vitro and in vivo. We have additionally found that MMP-8 is one of the key molecules for TRAIL release. We therefore hypothesize that CBM588 might be useful for a novel intravesical therapy against bladder cancer.

\section{Materials and methods}

Reagents. Clostridium butyricum MIYAIRI 588 (Miyarisan Pharma., Tokyo, Japan), BCG (Nippon Kayaku, Tokyo, Japan and Sanofi-Aventis, Tokyo, Japan), Lactobacillus casei (Yakult, Tokyo, Japan), Krestin (Daiichi Sankyo, Tokyo, Japan), Lentinan (Astellas Pharma, Tokyo, Japan) and IFN- $\alpha$ (Dainippon Sumitomo Pharma, Osaka, Japan) were dissolved in PBS. 5Z-7-oxozeaenol (Chugai Pharma., Tokyo, Japan), SB203580, SP600125 (Jena Bioscience, Jena, Germany), cathepsin G inhibitor (Santa Cruz Biotechnology, Santa Cruz, CA, USA), MMP-8 inhibitor and MMP-9 inhibitor (Merck, Darmstadt, Germany) were dissolved in dimethyl sulfoxide (DMSO). Cycloheximide, leupeptin and EDTA were purchased from Nacalai Tesque (Kyoto, Japan). Human recombinant DR5/Fc chimera and zVAD-fmk were obtained from R\&D Systems (Minneapolis, MN, USA). Actinomycin D and 1,10-phenanthroline were obtained from Sigma (St. Louis, MO, USA). Anti-human TLR2 and TLR4 were purchased from eBioscience (San Diego, CA, USA).

Cell culture. Human bladder cancer 253J-BV cells (24) provided by Dr K. Inoue (University of Kochi), human lung cancer H460, human renal cancer 786-O, human embryonic kidney HEK293 and murine bladder cancer MBT-2 cell lines were maintained in RPMI-1640 medium with $10 \%$ fetal bovine serum (FBS), $2 \mathrm{mM}$ glutamine, $100 \mathrm{U} / \mathrm{ml}$ penicillin and $100 \mu \mathrm{g} / \mathrm{ml}$ streptomycin. Normal PMNs were isolated using Polymorphprep (Axis-Shield, Oslo, Norway) and normal PBMCs were isolated using Lymphoprep (Axis-Shield), and maintained in RPMI-1640 medium with $10 \%$ FBS and $2 \mathrm{mM}$ glutamine. All cells were incubated at $37^{\circ} \mathrm{C}$ with humidity and $5 \% \mathrm{CO}_{2}$. PMNs and PBMCs were acquired from healthy volunteers after obtaining informed consent. This study was approved by the Kyoto Prefectural University of Medicine Research Ethics Committee (permission no. C-425 and C-919). All cell lines except 253J-BV used in this study were obtained from American Type Culture Collection (ATCC).

Enzyme-linked immunosorbent assay (ELISA). PMNs (2.5x10\% $\mathrm{ml}$ ) were incubated in the presence or absence of CBM588, $\mathrm{BCG}$, or other reagents for $6 \mathrm{~h}$. PMNs were centrifuged and the supernatant was collected. A human TRAIL ELISA kit (Abcam, Cambridge, UK) was used according to the manufacturer's instructions.

RNA isolation and quantification by real-time reverse transcription-PCR. RNA isolation and quantitative real-time RT-PCR were carried out as described (25). The real-time quantitative reverse transcription-PCR primer-probe sets for TRAIL mRNA (Hs00234355_m1) and GAPDH mRNA (Hs99999905_m1) were purchased from Applied Biosystems (Foster City, CA, USA).

Western blot analysis. Western blot analysis was carried out as described previously (25). Rabbit polyclonal MMP-8 (Chemicon, Temecula, CA, USA), MMP-9 (Abcam), caspase-3, and mouse specific caspase-8 (Cell Signaling Technology, Beverly, MA, USA) antibodies, and mouse monoclonal human TRAIL (Santa Cruz Biotechnology) and $\beta$-actin (Sigma) antibodies were used as the primary antibodies.

Stable transfection and siRNA transfection. The human TRAIL expression plasmid pCAGGS NEO-TRAIL was described previously (26). 786-O cells and HEK293 cells were transfected with pCAGGS NEO-TRAIL or pCAGGS NEO, a vacant vector plasmid, using Lipofectamine 2000 (Invitrogen, Carlsbad, CA, USA) according to the manufacturer's instructions. Transfected cells were selected in growth medium with $1 \mathrm{mg} / \mathrm{ml} \mathrm{G} 418$ (Sigma) and kept stable for more than 1 month before experiments.

siRNA transfections were carried out using Lipofectamine RNAiMAX Reagent (Invitrogen) according to the manufacturer's instructions. Briefly, $1 \times 10^{5}$ cells were seeded into 6-well tissue culture plates 1 day before transfection with 50 nM MMP-8 siRNA (Hs00233972_m1), MMP-9 siRNA (Hs00234579_m1), or a control siRNA (Silencer Select Negative Control \#2 siRNA) (Ambion, Austin, TX, USA). After $48 \mathrm{~h}$, we analyzed the culture medium of transfected cells by western blotting to evaluate the release of soluble TRAIL.

Generation of mutations in the transmembrane domain of TRAIL. Two constructs were generated, replacing the transmembrane domain of TRAIL using a site-directed mutagenesis kit (Stratagene, La Jolla, CA, USA). The first mutant construct (MT1) was obtained by substitution of the TRAIL transmembrane domain (residues 32-33: Ala-Val) with the peptide sequence (Ala-Asp). The second mutant (MT2) was replaced with the peptide sequence (Glu-Val).

Sequence analysis. The transmembrane domain of TRAIL was calculated using version 2.0 of TMHMM (http://www. cbs.dtu.dk/services/TMHMM/). SignalP (http://www.cbs.dtu. $\mathrm{dk} /$ services/SignalP/) was used for the prediction of signal peptides.

Detection of apoptosis. PMNs $\left(5 \times 10^{6} / \mathrm{ml}\right)$ were incubated in the presence or absence of CBM for $24 \mathrm{~h}$. PMNs were centrifuged and the supernatant was collected. Cancer cells were pretreated with the supernatant for $48 \mathrm{~h}$. DNA fragmentation was quantified by the percentage of hypodiploid DNA (sub-G1) as described previously (25).

Implantation of MBT-2 cells into $\mathrm{C} 3 \mathrm{H} / \mathrm{HeN}$ mice and the protocol in vivo. $\mathrm{C} 3 \mathrm{H} / \mathrm{HeN}$ female mice were obtained from Shimizu Laboratory Supplies (Kyoto, Japan). The present study complied with the principles and guidelines of the Japanese Council on Animal Care and it was also approved by the Committee for Animal Research of Kyoto Prefectural University of Medicine (permission no. M23-180). MBT-2 
A

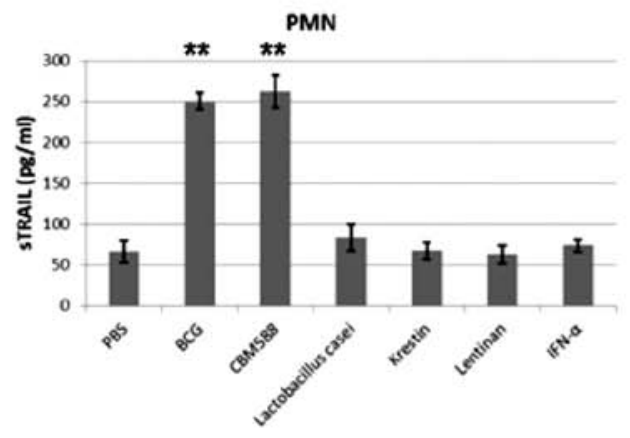

C

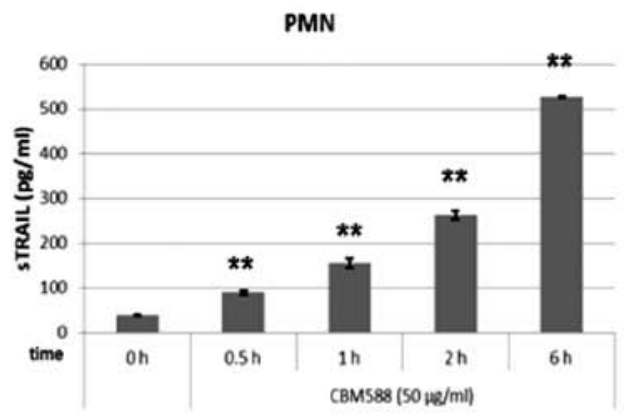

$\mathbf{E}$

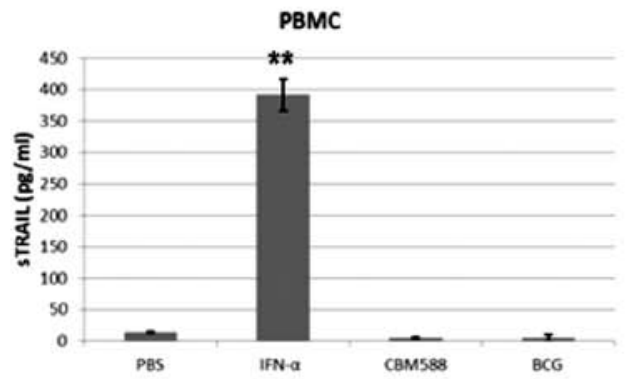

cells were harvested and resuspended in 1:1 PBS/Matrigel mixture. Cells $\left(2 \times 10^{5}\right)$ in $100 \mu$ l of mixture were injected s.c. into both flanks of each mouse. Mice were randomized into the following treatment groups $(n=3)$ : group I, untreated control (PBS, $100 \mu \mathrm{l} /$ tumor); group II, CBM588 (0.2 mg/tumor); and group III, BCG $(0.4 \mathrm{mg} /$ tumor$)$, once weekly, intratumor injection. Therapy was continued for 31 days. Tumor dimensions were measured with vernier calipers. Tumor volume was calculated using the formula: (shortest diameter) ${ }^{2} \mathrm{x}$ (longest diameter) $/ 2$. Tumor volume was compared among groups using an unpaired Student's t-test.

\section{Results}

Clostridium butyricum MIYAIRI 588 (CBM588) enhances the release of TRAIL from PMNs. It has been reported that
B

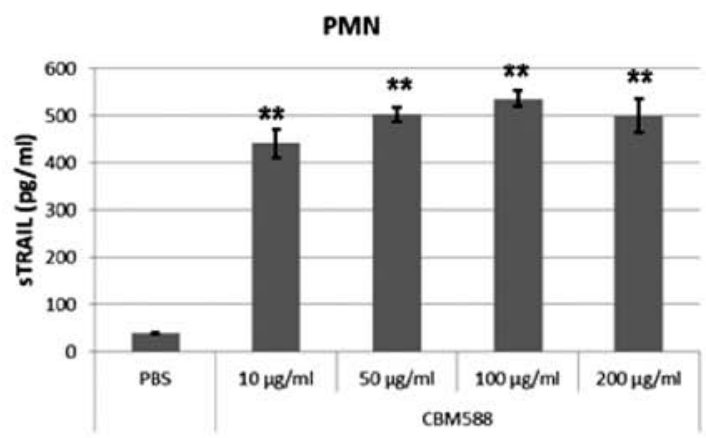

D

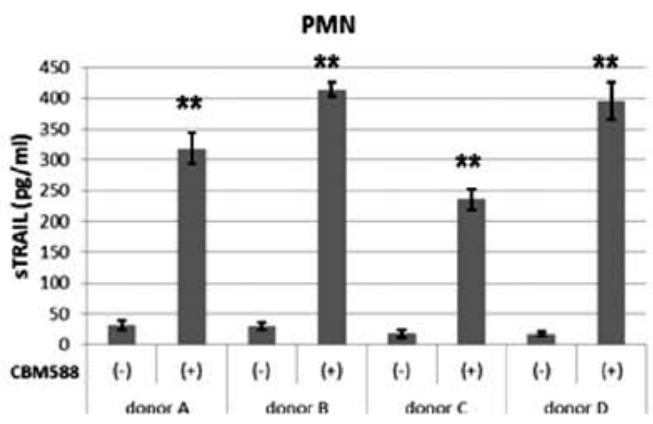

Figure 1. CBM588 enhances the release of TRAIL from PMNs. (A and B) Human PMNs or PBMCs were isolated from blood of healthy donors and seeded $\left(2.5 \times 10^{6}\right.$ cells $\left./ \mathrm{ml}\right)$. After incubation, the culture supernatant was assayed by ELISA for TRAIL. (A) PMNs were stimulated with BCG, CBM588, Lactobacillus casei, Krestin, Lentinan (each $10 \mu \mathrm{g} / \mathrm{ml}$ ) or IFN- $\alpha$ $(1,000 \mathrm{IU} / \mathrm{ml})$ for $6 \mathrm{~h}$. All bacteria were sterilized by heating. ${ }^{* *} \mathrm{P}<0.01$ versus PBS. (B) PMNs were stimulated with CBM588 at the doses indicated for 6 h. ${ }^{* *} \mathrm{P}<0.01$ versus PBS. (C) PMNs were stimulated with CBM588 $(50 \mu \mathrm{g} /$ $\mathrm{ml}$ ) for the period indicated. ${ }^{* *} \mathrm{P}<0.01$ versus PBS. (D) PMNs were isolated from different plural donors. Each donor's PMNs were stimulated with PBS or CBM588 $(50 \mu \mathrm{g} / \mathrm{ml})$ for $6 \mathrm{~h} .{ }^{* *} \mathrm{P}<0.01$ versus each donor's CBM588 (-). (E) PBMCs were stimulated with IFN- $\alpha(1,000 \mathrm{IU} / \mathrm{ml})$, CBM588 $(50 \mu \mathrm{g} / \mathrm{ml})$ or BCG $(100 \mu \mathrm{g} / \mathrm{ml})$ for $24 \mathrm{~h} .{ }^{* *} \mathrm{P}<0.01$ versus PBS. Columns, mean; bars, mean $\pm \mathrm{SD}$.

BCG stimulates the release of TRAIL from PMNs (12). We then evaluated whether other bacteria have similar effects. We added BCG, CBM588, Lactobacillus casei, Krestin (an extract from Trametes Versicolor), Lentinan (an extract from an edible mushroom), and IFN- $\alpha$ to PMNs for $6 \mathrm{~h}$ and measured concentrations of soluble TRAIL by ELISA. CBM588, as well as BCG, increased soluble TRAIL levels in the culture supernatant of PMNs, but the other bacteria and IFN- $\alpha$ did not (Fig. 1A).

Clostridium butyricum is a gram-positive anaerobe which produces butyric acid. It is found in soil or the intestines of animals and humans. The MIYAIRI 588 strain of Clostridium butyricum has been used as a probiotic for treating and preventing diarrhea or constipation $(27,28)$. MIYA-BM ${ }^{\circledR}$ tablets containing CBM588 were approved by the Japanese Ministry of Health and Welfare for clinical use in 
A

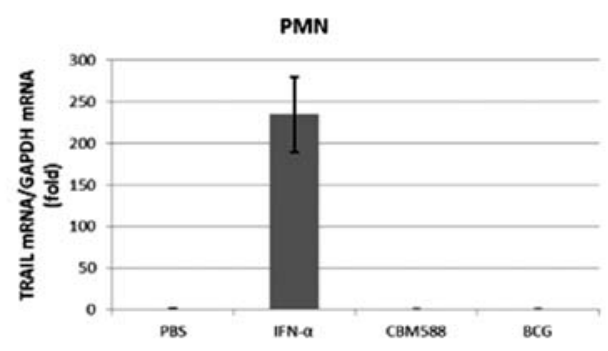

B

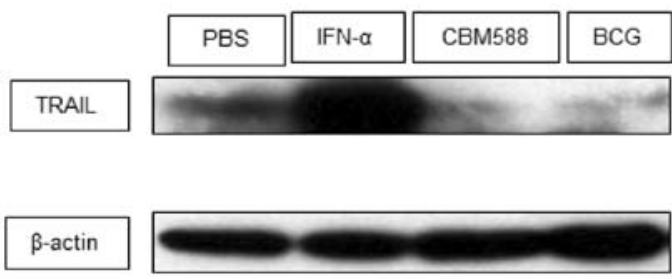

C

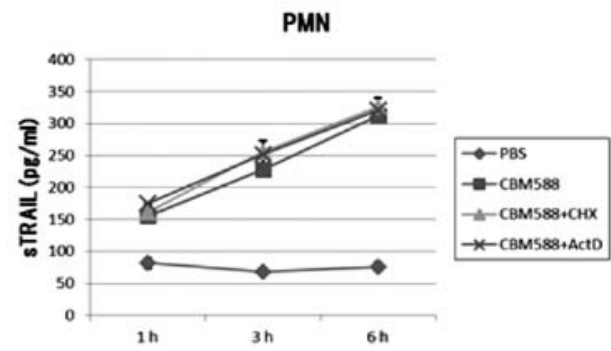

Figure 2. CBM588, similarly to BCG, does not induce TRAIL synthesis in PMNs. (A and B) Human PMNs were isolated from blood of healthy donors and seeded $\left(2.5 \times 10^{6}\right.$ cells $\left./ \mathrm{ml}\right)$. The cells were then treated with IFN- $\alpha$ (1,000 IU/ml), CBM588 $(50 \mu \mathrm{g} / \mathrm{ml})$, or BCG $(100 \mu \mathrm{g} / \mathrm{ml})$ for $6 \mathrm{~h}$. (A) Total RNA was isolated from PMNs and TRAIL mRNA levels were quantified by real-time PCR. (B) Isolated PMNs were lysed and TRAIL was detected by western blotting. (C) PMNs $\left(2.5 \times 10^{6}\right.$ cells $\left./ \mathrm{ml}\right)$ were treated with cycloheximide (CHX; $10 \mu \mathrm{g} / \mathrm{ml}$ ) or actinomycin D (ActD; $1 \mu \mathrm{g} / \mathrm{ml}$ ) for $1 \mathrm{~h}$ before stimulation with CBM588 $(50 \mu \mathrm{g} / \mathrm{ml})$. TRAIL levels in the culture supernatant at 1,3 and $6 \mathrm{~h}$ after CBM588 was added were measured by ELISA. Columns, mean; bars, mean \pm SD.

1970. Soluble TRAIL was drastically induced by CBM588 at $10 \mu \mathrm{g} / \mathrm{ml}$ or more (Fig. 1B) and time-dependently induced by $50 \mu \mathrm{g} / \mathrm{ml}$ of CBM588 (Fig. 1C). CBM588 similarly increased the release of TRAIL from the PMNs of all other donors' blood (Fig. 1D), while neither CBM588 nor BCG did so in peripheral blood mononuclear cells (PBMCs) (Fig. 1E). These results suggest that CBM588, as well as BCG, induces the release of TRAIL from PMNs, but not from PBMCs.

CBM588, similarly to BCG, does not induce TRAIL synthesis but stimulates the release of TRAIL from intracellular stores in PMNs. Kemp (12) reported that BCG did not increase
A

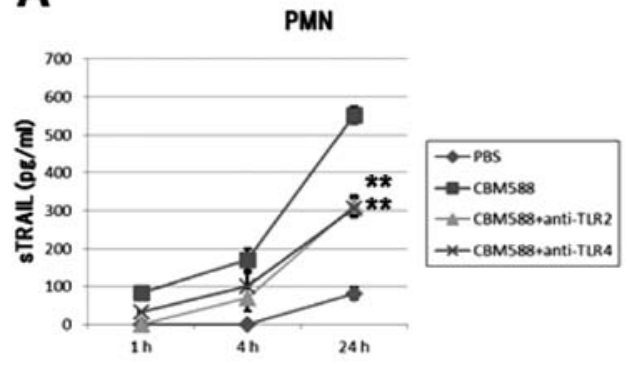

B
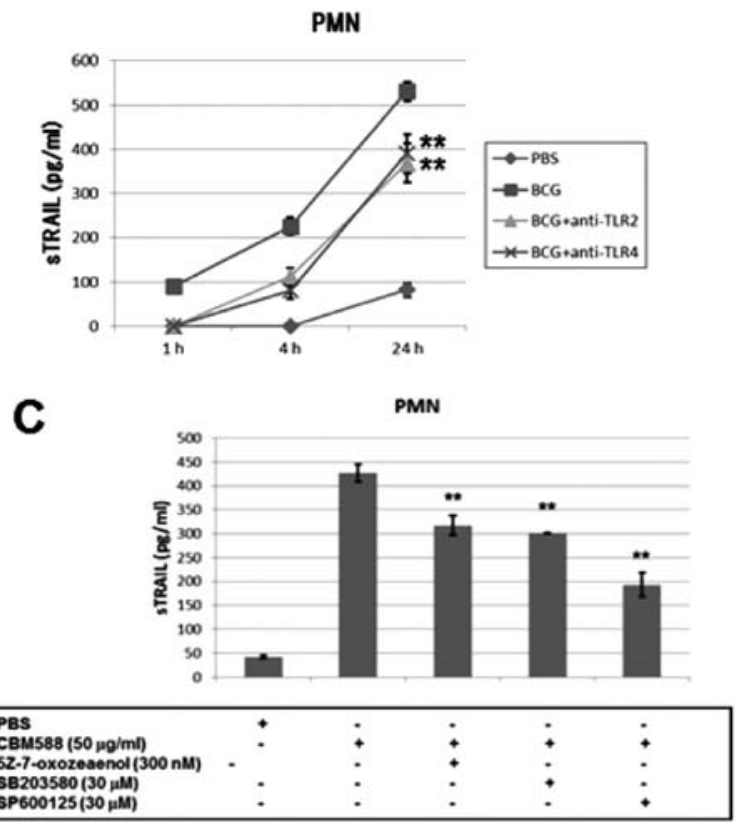

Figure 3. CBM588 induces the release of TRAIL from PMNs through TLR2/4 signaling. (A and B) Human PMNs were isolated from blood of healthy donors and seeded $\left(2.0 \times 10^{6}\right.$ cells $\left./ \mathrm{ml}\right)$. The cells were then treated with or without anti-human TLR2 or anti-human TLR4 antibody (each $20 \mu \mathrm{g} / \mathrm{ml})$ for $0.5 \mathrm{~h}$ and stimulated with CBM588 $(50 \mu \mathrm{g} / \mathrm{ml})$ or BCG $(100 \mu \mathrm{g} /$ $\mathrm{ml}$ ). TRAIL levels in the culture supernatant were examined by ELISA at 1,4 and $24 \mathrm{~h}$ after CBM588 or BCG was added. ${ }^{* *} \mathrm{P}<0.01$ versus CBM or BCG. (C) PMNs $\left(2.5 \times 10^{6}\right.$ cells $\left./ \mathrm{ml}\right)$ were treated with or without 5Z-7-oxozeaenol, SB203580 or SP600125 for $0.5 \mathrm{~h}$ and then stimulated with CBM588 for $6 \mathrm{~h}$. TRAIL levels in the culture supernatant were measured by ELISA. ** $\mathrm{P}<0.01$ versus CBM + DMSO. Columns, mean; bars, mean \pm SD.

TRAIL mRNA levels in PMNs and we have found that BCG or CBM588 did not induce TRAIL mRNA expression, whereas IFN- $\alpha$ did (Fig. 2A). We additionally evaluated the expression of the TRAIL protein in PMNs by western blotting. The amount of the protein was increased by IFN- $\alpha$, whereas it was decreased by CBM588 or BCG (Fig. 2B). Furthermore, to determine whether CBM588 or BCG induces de novo synthesis of TRAIL in PMNs, we treated PMNs with a protein or RNA synthesis inhibitor, cycloheximide $(10 \mu \mathrm{g} /$ $\mathrm{ml})$ or actinomycin D $(1 \mu \mathrm{g} / \mathrm{ml})$, respectively, for $1 \mathrm{~h}$ before adding CBM588 or BCG. The inhibitors did not suppress the release of TRAIL from PMNs (Fig. 2C). These results suggest that PMNs possess intracellular stores of TRAIL and that CBM588 or BCG induces the release of TRAIL from these stores without inducing TRAIL synthesis. 
CBM588 induces the release of TRAIL from PMNs through the TLR2/4 signaling pathway. Toll-like receptors (TLRs) play a role in mediating innate immune reactions $(29,30)$ and TLR2 and TLR4 have been reported to be involved in the host immune response to BCG $(31,32)$. Therefore, we evaluated whether TLR2 or TLR4 was associated with TRAIL release from PMNs by CBM588 or BCG. We stimulated PMNs with CBM588 or BCG for $6 \mathrm{~h}$ after incubating with TLR2 or TLR4 neutralization antibody for $0.5 \mathrm{~h}$ and then measured concentrations of soluble TRAIL using ELISA. TLR2 or TLR4 neutralization antibody inhibited the release of TRAIL by CBM588 or BCG (Fig. 3A and B). Inhibition of the downstream pathway of TLR2 or TLR4 by a TAK1 inhibitor 5Z-7-oxozeaenol (33), a p38 MAPK inhibitor SB203580 and a JNK inhibitor SP600125 suppressed the release of TRAIL by CBM588 (Fig. 3C). CBM588 or BCG upregulated the phosphorylation of p38 and JNK in PMNs (data not shown). These results strongly suggest that CBM588 or BCG releases TRAIL from PMNs at least partially through a TLR 2 or TLR4 signaling pathway.

MMP-8 is one of the key molecules for the release of TRAIL from PMNs. To determine what protease was associated with the release of TRAIL from PMNs, we examined whether protease inhibitors suppressed the release. Among the inhibitors examined, general MMP inhibitors, such as 1,10-phenanthroline and EDTA, markedly decreased the concentration of soluble TRAIL in the culture supernatant of PMNs stimulated by CBM588 or BCG (Fig. 4A and B), while the cathepsin $\mathrm{G}$ inhibitor had only a slight effect. PMNs are known to have abundant MMP- 8 and -9 , and therefore we examined the effect of an MMP- 8 or -9 specific inhibitor on the release of TRAIL by CBM588. As shown in Fig. 4C, the MMP-8 specific inhibitor suppressed the accelerated release of TRAIL by CBM588, whereas the MMP-9 specific inhibitor only weakly inhibited the release. When PMNs are activated, MMPs are released from their granules to the extracellular area (34-36). We therefore detected MMP-8 and -9 in culture supernatant by western blotting and found that CBM588 drastically increased MMP-8 and -9 protein levels. Whereas the MMP-8 level was decreased by 5Z-7-oxozeaenol, SB203580 or SP600125, the level of MMP-9 was not changed (Fig. 4D). These results suggest that MMP-8 at least partially releases TRAIL and is regulated by TLR $2 / 4$ downstream signaling.

We next examined the effects of MMP-8/9 siRNA on the release of TRAIL. We transfected the TRAIL expression vector into TRAIL-resistant human renal cancer 786-O cells, and established a stable TRAIL-expressing cell line. Subsequently, we transiently transfected MMP-8 siRNA or MMP-9 siRNA into this cell line. As shown in Fig. 4E, knockdown of MMP-8, but not MMP-9, decreased TRAIL levels in the culture supernatant. Therefore, this result strongly suggests that MMP-8 is crucial to the release of TRAIL. Fig. 4F shows the amino acid sequence of human TRAIL, including a putative transmembrane domain identified using TMHMM. Using SignalP 3.0, we found a proteolytic cleavage site of TRAIL, which could be digested by MMP- 8 and -9 . We constructed plasmids with a mutation at this site, and named them MT1 and MT2 (Fig. 4G). As shown in Fig. 4H, the introduction of a mutation at the putative proteolytic cleavage site remark- ably inhibited the release of TRAIL from TRAIL-expressing HEK 293 cells. Therefore, these results clearly show that the site is absolutely necessary for the release of TRAIL and that MMP-8 is a candidate for the proteolytic enzyme of TRAIL.

Release of TRAIL from PMNs stimulated by CBM588 results in the apoptosis of human cancer cells in vitro. A recent study demonstrated that BCG enhanced the cytotoxicity of PMNs against bladder cancer cells (37). We then added CBM588 to PMNs, and found that the supernatant drastically enhanced the apoptosis of human lung cancer H460 cells (Fig. 5A). The pan-caspase inhibitor zVAD-fmk inhibited apoptosis, while a dominant negative protein against DR5, the DR5/Fc chimera, partially inhibited it (Fig. 5A). We also confirmed the results by crystal violet staining, and found that CBM588 alone had little effect on cancer cell death (data not shown). We performed the next experiment using bladder cancer 253J-BV cells and found that apoptosis was similarly induced by PMNs with CBM588 and inhibited by zVAD-fmk or 5Z-7-oxozeaenol, a TAK1 inhibitor (Fig. 5B). These results suggest that TRAIL released from PMNs by CBM588 induces caspase-dependent apoptosis of cancer cells.

CBM588 suppresses the growth of murine bladder cancer cells in $\mathrm{C} 3 \mathrm{H} / \mathrm{HeN}$ mice. Previous studies showed that BCG induced antitumor effects against bladder cancer cells in vivo $(37,38)$. We then examined the effects of CBM588 and BCG against murine bladder cancer MBT-2 cells inoculated in $\mathrm{C} 3 \mathrm{H} / \mathrm{HeN}$ mice. As shown in Fig. 6A, on day 0, MBT-2 cells were subcutaneously inoculated into both flanks of mice. On days 3, 10, 17 and 24, CBM588, BCG or PBS as a control was injected into each tumor. The tumor volume was measured by vernier calipers on each day indicated. A significant difference in weight was not observed among the three groups (Fig. 6B). Intratumor injection of BCG partially suppressed tumor growth, while CBM588 almost completely inhibited it (Fig. 6C). We additionally evaluated the activation of caspase-8 and -3 in tumor cell lysate by western blotting. We detected the cleaved form of caspase- 8 and -3 from lysate of tumors treated with CBM588 or BCG (Fig. 6D). These results suggest that CBM588 is also useful in vivo to suppress the growth of bladder cancer cells.

\section{Discussion}

$\mathrm{BCG}$ is recognized as one of the most effective agents against superficial bladder cancer. Despite great effort, however, the serious side effects of BCG, such as disseminated infections, sepsis, and multiple organ failure $(7,8)$ have yet to be eliminated. In addition, the best use of BCG has not been clearly determined, because of a poor understanding of its mechanisms of action. It is therefore necessary to clarify the antitumor mechanisms of BCG for safer and more effective use.

In the present study, we found that the non-toxic and harmless Clostridium, CBM588, drastically suppressed the growth of bladder cancer cells in vitro and in vivo. CBM588 is known to be a component of intestinal bacterial flora. This strain has been shown to be non-toxic and harmless unlike other Clostridium and is commonly used as a probiotic for diarrhea 
A

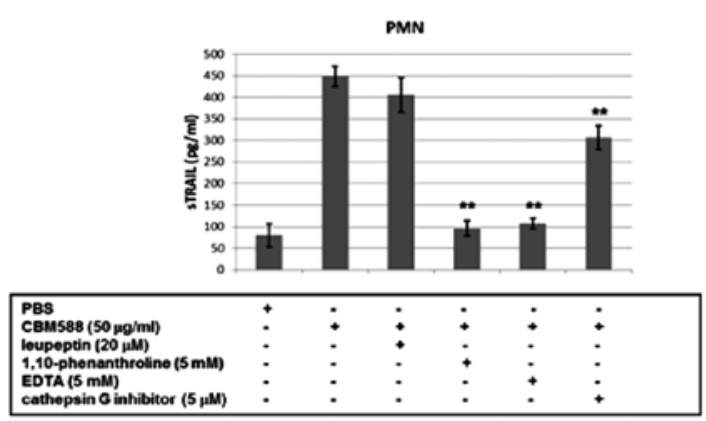

C

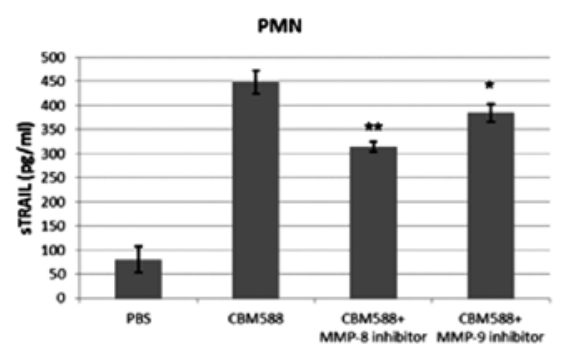

B

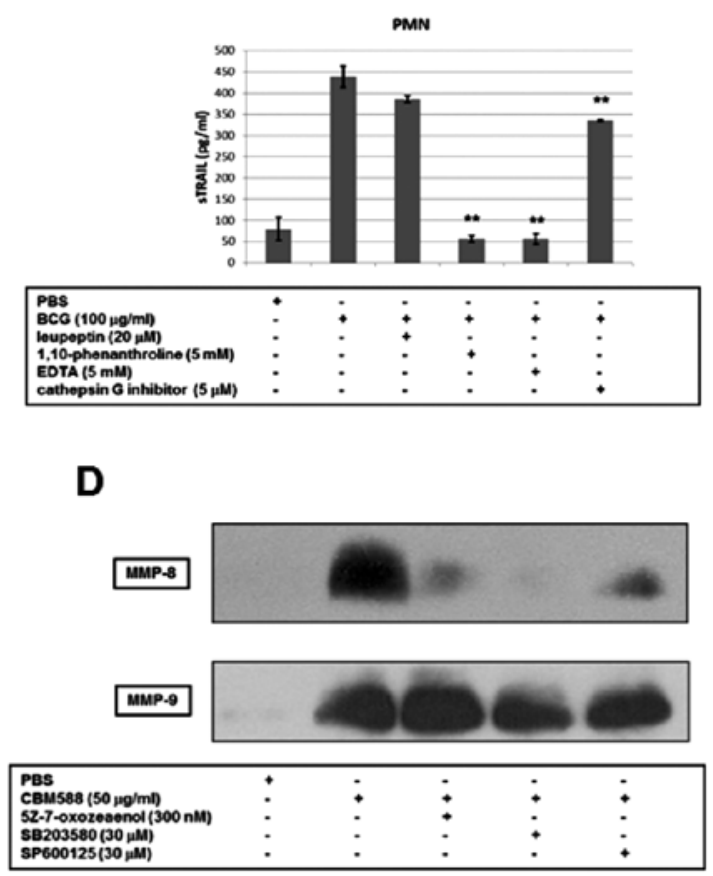

E

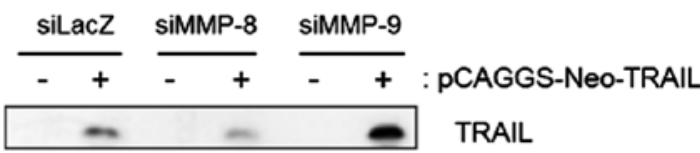

$\mathbf{F}$

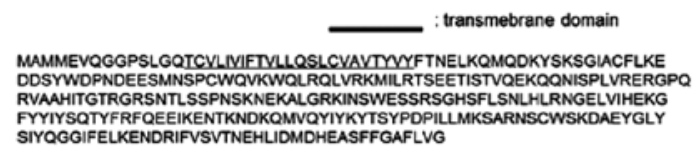

G

$\begin{array}{ll}\text { WT } & \text { TCVLIVIFTVLLQSLCVAVTYY } \\ \text { MT1 } & \text { TCVLIVIFTVLLQSLCVADTYYY } \\ \text { MT2 } & \text { TCVLIVIFTVLLQSLCVEVTTYY }\end{array}$

H

TRAIL vector

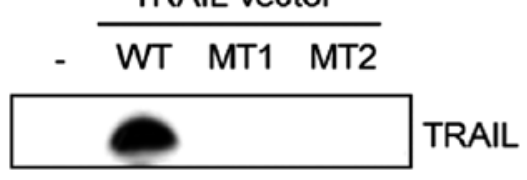

Figure 4. MMP-8 is one of the key molecules for the release of TRAIL from PMNs. (A and B) Human PMNs were isolated from blood of healthy donors and seeded $\left(2.5 \times 10^{6}\right.$ cells $\left./ \mathrm{ml}\right)$. The cells were treated with or without leupeptin, 1,10-phenanthroline, EDTA and cathepsin $\mathrm{G}$ inhibitor for $0.5 \mathrm{~h}$ and then stimulated with CBM588 or BCG for an additional $6 \mathrm{~h}$. TRAIL levels in the culture supernatant were analyzed by ELISA. ${ }^{* *} \mathrm{P}<0.01$ versus CBM or BCG. (C) PMNs $\left(2.5 \times 10^{6}\right.$ cells $\left./ \mathrm{ml}\right)$ were treated with or without an MMP-8 inhibitor $(50 \mu \mathrm{M})$ or MMP-9 inhibitor $(50 \mu \mathrm{M})$ for $0.5 \mathrm{~h}$ and PMNs were stimulated with CBM588 $(50 \mu \mathrm{g} / \mathrm{ml})$ for $6 \mathrm{~h}$. TRAIL levels in the culture supernatant were analyzed by ELISA. ${ }^{*} \mathrm{P}<0.05$ versus $\mathrm{CBM}$; ${ }^{* *} \mathrm{P}<0.01 \mathrm{versus} \mathrm{CBM}$. (D) PMNs $\left(2.5 \mathrm{x} 10^{6}\right.$ cells $\left./ \mathrm{ml}\right)$ were treated with or without 5Z-7-oxozeaenol, SB203580, or SP600125 for $0.5 \mathrm{~h}$ and PMNs were stimulated with CBM588 for $2 \mathrm{~h}$. Culture supernatants were analyzed by western blotting. (E) MMP-8 or -9 was knocked down in stably transfected 786-O cells expressing TRAIL. After 48 h, culture supernatants were analyzed by western blotting. (F) The amino acid sequence of human TRAIL and a putative transmembrane domain of TRAIL (underlined). (G) Sequence of the transmembrane domain of TRAIL with or without the mutation of each plasmid. (H) These mutation plasmids were transfected into HEK293 cells expressing TRAIL. After $48 \mathrm{~h}$, culture supernatants were analyzed by western blotting. Columns, mean; bars, mean \pm SD.

(39). Therefore, CBM588 is promising for the novel and safer treatment of superficial bladder cancer.

We found that CBM588 as well as BCG induced the release of TRAIL from intracellular stores in PMNs, while they did not enhance TRAIL synthesis. On the other hand, it has been reported that a combination of intravesical BCG with IFN- $\alpha$ was effective $(40,41)$. IFN- $\alpha$ upregulates the transcription of TRAIL in PMNs (12) and therefore it might be more effective for CBM588 intravesical therapy to use IFN- $\alpha$. Furthermore, CBM588 shows promise in combina- 
A

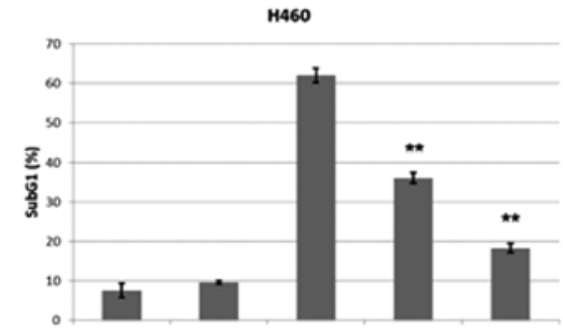

\begin{tabular}{|c|c|c|c|c|c|}
\hline $\begin{array}{l}\text { PMN }\left(5.0 \times 10^{6} \text { cells } / \mathrm{ml}\right) \\
\text { PBS } \\
\text { CBM588 }(50 \mu \mathrm{g} / \mathrm{ml}) \\
\text { DR5/Fc chimera }(1 \mu \mathrm{g} / \mathrm{ml}) \\
\text { zVAD-fmk }(20 \mu M)\end{array}$ & $:$ & $\stackrel{+}{:}$ & $\stackrel{+}{*}$ & + & + \\
\hline
\end{tabular}

B

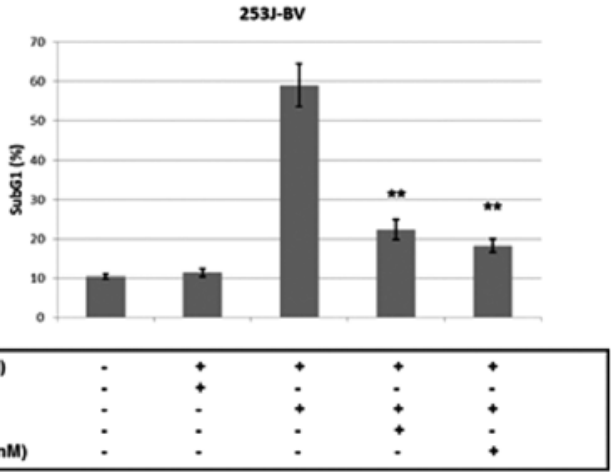

Figure 5. Release of TRAIL from PMNs stimulated by CBM588 results in the apoptosis of human cancer cells in vitro. (A and B) PMNs $\left(5.0 \times 10^{6}\right.$ cells/ $\mathrm{ml}$ ) were incubated with or without CBM588, DR5/Fc chimera, zVAD-fmk or $5 \mathrm{Z}-7$-oxozeaenol for $24 \mathrm{~h}$. After centrifugation, the culture supernatant was collected and added to lung cancer $\mathrm{H} 460$ cells $\left(2.5 \times 10^{4}\right.$ cells $\left./ \mathrm{ml}\right)(\mathrm{A})$, or bladder cancer $253 \mathrm{~J}-\mathrm{BV}$ cells $\left(2.5 \times 10^{4}\right.$ cells $\left./ \mathrm{ml}\right)(\mathrm{B})$. After $48 \mathrm{~h}$, apoptosis was analyzed by flow cytometry. ${ }^{* *} \mathrm{P}<0.01$ versus PMNs with CBM588. Columns, mean; bars, mean $\pm \mathrm{SD}$.

tion with various agents enhancing sensitivity to TRAIL, such as inducers of a TRAIL receptor, death receptor (DR) 5 . We previously reported a variety of agents upregulating DR5 expression $(25,42,43)$. Among them, sulforaphane in broccoli sprouts might be useful in combination with the intravesical CBM588 therapy, because of its own antitumor effects (44) and effective transition to urine (45).

The proteolytic activities of various proteases, such as lysosomal cathepsins and MMPs, have been associated with many malignant tumors $(46,47)$. However, several strategies designed to broadly block MMPs have not been successful as cancer therapy, perhaps due to their functional diversity in vivo $(48,49)$. For example, several MMPs, such as MMP-3, -8 and -12 , were found to have antitumorigenic effects through the suppression of tumor angiogenesis and degradation of chemokines that mediate organ-specific metastasis (47). In the present study, we demonstrated that MMP-8 induced the release of TRAIL, consistent with the hypothesis described above.

In conclusion, we have found that CBM588 is safer than BCG and effective against human bladder cancer cells in vitro
A

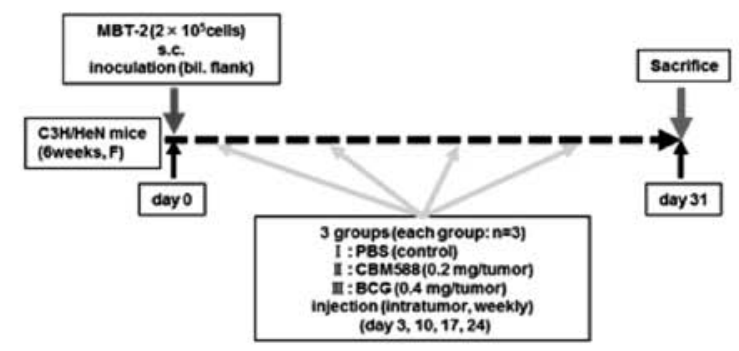

B

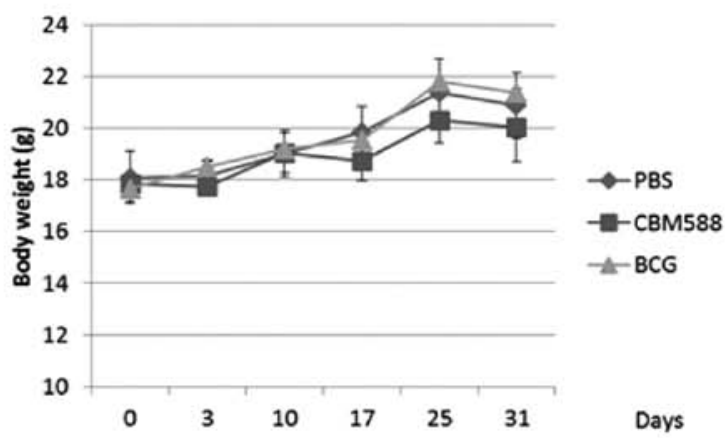

C
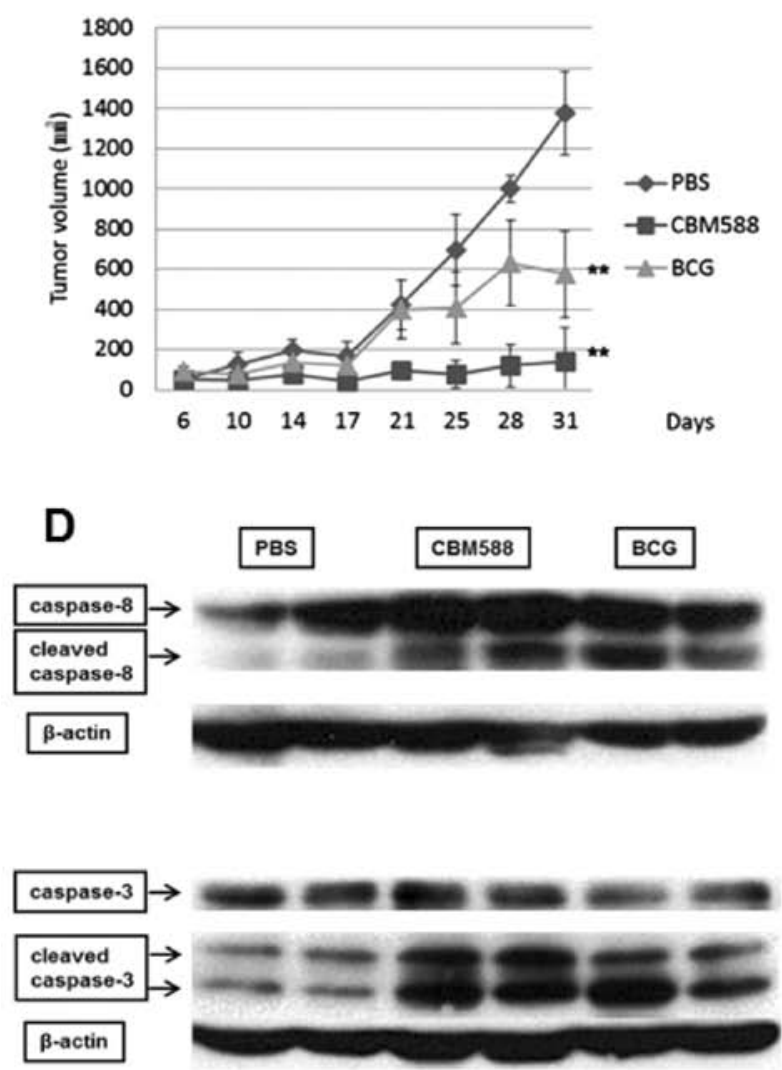

Figure 6. CBM588 suppresses the growth of murine bladder cancer cells in $\mathrm{C} 3 \mathrm{H} / \mathrm{HeN}$ mice. (A) Schematic representation of the experimental protocol described in Materials and methods. Animals were divided into 3 groups $(\mathrm{n}=3)$. Group I was treated with PBS $(100 \mu 1 /$ tumor $)$, group II was treated with CBM588 (0.2 mg/tumor) and group III was treated with BCG $(0.4 \mathrm{mg} /$ tumor). (B) The change of murine body weight in each group. (C) The tumor volume of each mouse was measured on the days indicated. ${ }^{* *} \mathrm{P}<0.01$ versus PBS. (D) Isolated murine tumors were lysed, and caspase- 8 and -3 were detected by western blotting. Columns, mean; bars, mean \pm SD. 
and in vivo. We additionally clarified that TRAIL release by CBM588 is important for the antitumor effect and that MMP-8 is one of the key molecules responsible for the release. We believe that this discovery will lead to a novel intravesical therapy for bladder cancer.

\section{Acknowledgments}

The authors thank Drs K. Inoue and C.P. Dinney for generously providing the human bladder cancer cell line 253J-BV and Dr T. Yoshida for helpful discussions. The gifts of Clostridium butyricum MIYAIRI 588 from Miyarisan Pharmaceutical, BCG from Nippon Kayaku and Sanofi-Aventis Pharmaceutical, and 5Z-7-oxozeaenol from Chugai Pharmaceutical are gratefully acknowledged. This study was partly supported by the Japanese Ministry of Education, Culture, Sports, Science and Technology (22790547 to M. Horinaka).

\section{References}

1. Jemal A, Siegel R, Xu J and Ward E: Cancer statistics, 2010. CA Cancer J Clin 60: 277-300, 2010.

2. Devesa SS, Blot WJ, Stone BJ, Miller BA, Tarone RE and Fraumeni JF Jr: Recent cancer trends in the United States. J Natl Cancer Inst 87: 175-182, 1995.

3. Hasui Y, Osada Y, Kitada S and Nishi S: Significance of invasion to the muscularis mucosae on the progression of superficial bladder cancer. Urology 43: 782-786, 1994.

4. Crispen R: History of BCG and its substrains. Prog Clin Biol Res 310: 35-50, 1989.

5. Morales A, Eidinger D and Bruce AW: Intracavitary Bacillus Calmette-Guerin in the treatment of superficial bladder tumors. J Urol 116: 180-183, 1976.

6. Herr HW and Morales A: History of bacillus Calmette-Guerin and bladder cancer: an immunotherapy success story. J Urol 179: 53-56, 2008.

7. Borre S, Brustia D, Rosa F, Brondolo R, Rizzo G and Garavelli PL: Calmette-Guerin bacillus disseminated infection after intravesical instillation. Recenti Prog Med 93: 247-248, 2002 (In Italian).

8. Elmer A, Bermes U, Drath L, Buscher E and Viertel A: Sepsis and multiple organ failure after BCG-instillation for bladder cancer. Internist 45: 935-939, 2004 (In German).

9. Takahashi T, Kushiro A, Nomoto K, et al: Antitumor effects of the intravesical instillation of heat killed cells of the Lactobacillus casei strain Shirota on the murine orthotopic bladder tumor MBT-2. J Urol 166: 2506-2511, 2001.

10. Seow SW, Cai S, Rahmat JN, et al: Lactobacillus rhamnosus GG induces tumor regression in mice bearing orthotopic bladder tumors. Cancer Sci 101: 751-758, 2010.

11. Ludwig AT, Moore JM, Luo Y, et al: Tumor necrosis factorrelated apoptosis-inducing ligand: a novel mechanism for Bacillus Calmette-Guerin-induced antitumor activity. Cancer Res 64: 3386-3390, 2004.

12. Kemp TJ: Neutrophil stimulation with Mycobacterium bovis bacillus Calmette-Guerin (BCG) results in the release of functional soluble TRAIL/Apo-2L. Blood 106: 3474-3482, 2005.

13. Wiley SR, Schooley K, Smolak PJ, et al: Identification and characterization of a new member of the TNF family that induces apoptosis. Immunity 3: 673-682, 1995.

14. Ashkenazi A, Pai RC, Fong S, et al: Safety and antitumor activity of recombinant soluble Apo2 ligand. J Clin Invest 104: 155-162, 1999.

15. Walczak H, Miller RE, Ariail K, et al: Tumoricidal activity of tumor necrosis factor-related apoptosis-inducing ligand in vivo. Nat Med 5: 157-163, 1999.

16. Fesik SW: Promoting apoptosis as a strategy for cancer drug discovery. Nat Rev Cancer 5: 876-885, 2005.

17. Soria JC, Smit E, Khayat D, et al: Phase 1 b study of dulanermin (recombinant human Apo2L/TRAIL) in combination with paclitaxel, carboplatin, and bevacizumab in patients with advanced non-squamous non-small-cell lung cancer. J Clin Oncol 28 $1527-1533,2010$
18. Schonbeck U, Mach F and Libby P: Generation of biologically active IL-1 beta by matrix metalloproteinases: a novel caspase1-independent pathway of IL-1 beta processing. J Immunol 161: 3340-3346, 1998

19. Van den Steen PE, Proost P, Wuyts A, Van Damme J and Opdenakker G: Neutrophil gelatinase B potentiates interleukin-8 tenfold by aminoterminal processing, whereas it degrades CTAP-III, PF-4, and GRO-alpha and leaves RANTES and MCP-2 intact. Blood 96: 2673-2681, 2000.

20. McQuibban GA, Gong JH, Tam EM, McCulloch CA, ClarkLewis I and Overall CM: Inflammation dampened by gelatinase A cleavage of monocyte chemoattractant protein-3. Science 289: 1202-1206, 2000.

21. Black RA, Rauch CT, Kozlosky CJ, et al: A metalloproteinase disintegrin that releases tumour-necrosis factor-alpha from cells. Nature 385: 729-733, 1997.

22. Kawakubo T, Okamoto K, Iwata J, et al: Cathepsin E prevents tumor growth and metastasis by catalyzing the proteolytic release of soluble TRAIL from tumor cell surface. Cancer Res 67: 10869-10878, 2007.

23. Weinlich R, Brunner T and Amarante-Mendes GP: Control of death receptor ligand activity by posttranslational modifications. Cell Mol Life Sci 67: 1631-1642, 2010.

24. Dinney CP, Fishbeck R, Singh RK, et al: Isolation and characterization of metastatic variants from human transitional cell carcinoma passaged by orthotopic implantation in athymic nude mice. J Urol 154: 1532-1538, 1995.

25. Taniguchi H, Yoshida T, Horinaka M, et al: Baicalein overcomes tumor necrosis factor-related apoptosis-inducing ligand resistance via two different cell-specific pathways in cancer cells but not in normal cells. Cancer Res 68: 8918-8927, 2008.

26. Matsubara H, Mizutani Y, Hongo F, et al: Gene therapy with TRAIL against renal cell carcinoma. Mol Cancer Ther 5: 2165-2171, 2006

27. Okamoto T, Sasaki M, Tsujikawa T, Fujiyama Y, Bamba T and Kusunoki M: Preventive efficacy of butyrate enemas and oral administration of Clostridium butyricum M588 in dextran sodium sulfate-induced colitis in rats. J Gastroenterol 35: 341-346, 2000.

28. Seki H, Shiohara M, Matsumura T, et al: Prevention of antibiotic-associated diarrhea in children by Clostridium butyricum MIYAIRI. Pediatr Int 45: 86-90, 2003.

29. Akira S, Takeda $\mathrm{K}$ and Kaisho T: Toll-like receptors: critical proteins linking innate and acquired immunity. Nat Immunol 2: 675-680, 2001

30. Takeda K and Akira S: Roles of Toll-like receptors in innate immune responses. Genes Cells 6: 733-742, 2001.

31. Heldwein KA, Liang MD, Andresen TK, et al: TLR2 and TLR4 serve distinct roles in the host immune response against Mycobacterium bovis BCG. J Leukoc Biol 74: 277-286, 2003.

32. Godaly G and Young DB: Mycobacterium bovis bacille Calmette Guerin infection of human neutrophils induces CXCL8 secretion by MyD88-dependent TLR2 and TLR4 activation. Cell Microbiol 7: 591-601, 2005.

33. Ninomiya-Tsuji J, Kajino $\mathrm{T}$, Ono $\mathrm{K}$, et al: A resorcylic acid lactone, 5Z-7-oxozeaenol, prevents inflammation by inhibiting the catalytic activity of TAK1 MAPK kinase kinase. J Biol Chem 278: 18485-18490, 2003.

34. Owen CA,HuZ,Lopez-Otin C and Shapiro SD: Membrane-bound matrix metalloproteinase- 8 on activated polymorphonuclear cells is a potent, tissue inhibitor of metalloproteinase-resistant collagenase and serpinase. J Immunol 172: 7791-7803, 2004.

35. Pei D: Leukolysin/MMP25/MT6-MMP: a novel matrix metalloproteinase specifically expressed in the leukocyte lineage. Cell Res 9: 291-303, 1999.

36. Faurschou M and Borregaard N: Neutrophil granules and secretory vesicles in inflammation. Microbes Infect 5: 1317-1327, 2003.

37. Kamat AM, Tharakan ST, Sung B and Aggarwal BB: Curcumin potentiates the antitumor effects of Bacillus Calmette-Guerin against bladder cancer through the downregulation of NF- $\mathrm{\kappa B}$ and upregulation of TRAIL receptors. Cancer Res 69: 8958-8966, 2009.

38. Fujii H, Saimoto A, Nishikawa K, Yamazaki S and Kameyama S: Effect of BCG Connaught strain on mouse bladder tumor models. Biotherapy 17: 167-173, 2003.

39. Shimbo I, Yamaguchi T, Odaka T, et al: Effect of Clostridium butyricum on fecal flora in Helicobacter pylori eradication therapy. World J Gastroenterol 11: 7520-7524, 2005. 
40. Stricker P, Pryor K, Nicholson T, et al: Bacillus Calmette-Guerin plus intravesical interferon alpha-2b in patients with superficial bladder cancer. Urology 48: 952-961, 1996.

41. Esuvaranathan K, Chiong E, Thamboo TP, et al: Predictive value of $\mathrm{p} 53$ and $\mathrm{pRb}$ expression in superficial bladder cancer patients treated with BCG and interferon-alpha. Cancer 109: 1097-1105, 2007.

42. Yoshida T, Horinaka M and Sakai T: 'Combination-oriented molecular-targeting prevention' of cancer: a model involving the combination of TRAIL and a DR5 inducer. Environ Health Prev Med 15: 203-210, 2010.

43. Matsui TA, Sowa Y, Yoshida T, et al: Sulforaphane enhances TRAIL-induced apoptosis through the induction of DR5 expression in human osteosarcoma cells. Carcinogenesis 27: 1768-1777, 2006.

44. Shan Y, Sun C, Zhao X, Wu K, Cassidy A and Bao Y: Effect of sulforaphane on cell growth, $\mathrm{G}(0) / \mathrm{G}(1)$ phase cell progression and apoptosis in human bladder cancer T24 cells. Int J Oncol 29 883-888, 2006.
45. Munday R, Mhawech-Fauceglia P, Munday CM, et al: Inhibition of urinary bladder carcinogenesis by broccoli sprouts. Cancer Res 68: 1593-1600, 2008.

46. Nomura $\mathrm{T}$ and Katunuma N: Involvement of cathepsins in the invasion, metastasis and proliferation of cancer cells. J Med Invest 52: 1-9, 2005.

47. Overall CM and Kleifeld O: Tumour microenvironment opinion: validating matrix metalloproteinases as drug targets and anti-targets for cancer therapy. Nat Rev Cancer 6: 227-239, 2006.

48. Coussens LM, Fingleton B and Matrisian LM: Matrix metalloproteinase inhibitors and cancer: trials and tribulations. Science 295: 2387-2392, 2002

49. Overall CM and Lopez-Otin C: Strategies for MMP inhibition in cancer: innovations for the post-trial era. Nat Rev Cancer 2: 657-672, 2002. 